\title{
POLYETHYLENE GLYCOLS AS EMBEDDING MEDIA IN HISTOCHEMICAL WORK
}

\author{
BY \\ S. SRIRAMACHARI AND V. RAMALINGASWAMI \\ From the Nutrition Research Laboratories of the Indian Council of Medical Research, Coonoor, \\ South India
}

(RECEIVED FOR PUBLICATION MAY 9, 1952)

The embedding and sectioning of tissues in paraffin is a slow process. For histochemical purposes, especially for the demonstration of enzymes, preparation of tissue sections in paraffin is not desirable since the exposures of tissues to high temperatures and to several changes of dehydrating and clearing agents are detrimental to the preservation of enzymes.

Gomori's (1946) experience with the technique of histochemical demonstration of acid phosphatase led him to state that "for some reason, the staining for acid phosphatase turns out patchy, occasionally even negative, when it should be positive. This seems to happen, especially in cases when the pieces have been exposed to the temperature of the paraffin oven for more than an hour or when the temperature of the oven is over $56^{\circ}$ C." Several investigators (Danielli, 1946; Stafford and Atkinson, 1948 ; Rabinovitch, Junqueira, and Fajer, 1949) demonstrated severe loss of acid and alkaline phosphatase activity during paraffin embedding of tissues. Montagna and Noback (1947) thought that acid phosphatase was partially denatured during infiltration in paraffin and felt it advisable to eliminate the paraffin method from the technique wherever possible. Rheingold and Wislocki (1948) also find that in the case of both acid and alkaline phosphatase far more phosphatase is visible in smears of bone marrow than in sectioned material prepared by the paraffin method. In the case of other enzymes also loss of activity is likely to occur due to the several factors discussed above. The paraffin method suffers from the further disadvantage that the sections are not suitable for the demonstration of lipoids. It is clear, therefore, that a rapid method of embedding and sectioning tissues without the disadvantages of the paraffin method is required in histochemical work when enzymes and lipoids are being studied. We present observations on a rapid method of sectioning tissues in polyethylene glycols which is free from these disadvantages.

Synthetic, water-soluble, wax-like polyethylene glycols have been used successfully in recent years for the preparation of tissue sections. They were introduced by Richards, Anderson, and Hance (1942) for preparing sections of muscle of $0.25 \mu$ thickness for electron microscopy. Carsten (1947) dehydrated and embedded eyes in polyethylene glycols and found this technique to be superior to the usual paraffin and celloidin methods. Blank (1949), and Blank and McCarthy (1950) found these compounds advantageous when they prepared sections from a number of tissues for routine staining. Firminger (1950) and Rinehart and Abul-Haj (1951) used them successfully for the demonstration of lipoids.

The polyethylene glycols have the general formula $\mathrm{HOCH}_{2}\left(\mathrm{CH}_{2} \mathrm{OCH}_{2}\right)_{x} \mathrm{CH}_{2} \mathrm{OH}$. Those with an average mo'ecular weight of 1000 and above are wax-like solids.* With increasing molecular weights they become less water-soluble and less hygroscopic. They are inert, non-corrosive compounds and do not extract cell components like fat, glycogen, and nucleoproteins. They are not only good embedding media of varying hardness and melting ranges, but also serve as effective dehydrating agents without causing drastic shrinkage of tissues. Thus, with this method, dehydration, infiltration, and embedding are achieved with the same compound and the entire process is reduced to a few hours. By using the lower members of the polyethylene glycols such as "carbowax 1000," which has a fairly hard consistency and a melting range of $35^{\circ} \mathrm{C}$. to $40^{\circ} \mathrm{C}$., the temperature of incubation of tissues is also markedly reduced. It was thought, therefore, that these compounds could have an important application in histochemical work, especially for the study of enzymes.

In a critical review of micromethods in the study of enzyme distribution in cells and tissues Holter and Linderström-Lang (1951) state:

" The use of 'carbowax' (polyethylene glycol) as a medium is very promising too, since the

"They are marketed under the trade mark "carbowax" by the Carbide and Carbon Chemical Corporation. New York, and are designated by their molecular weights such as "carbowax 1000," “ carbowax 4000," etc. 


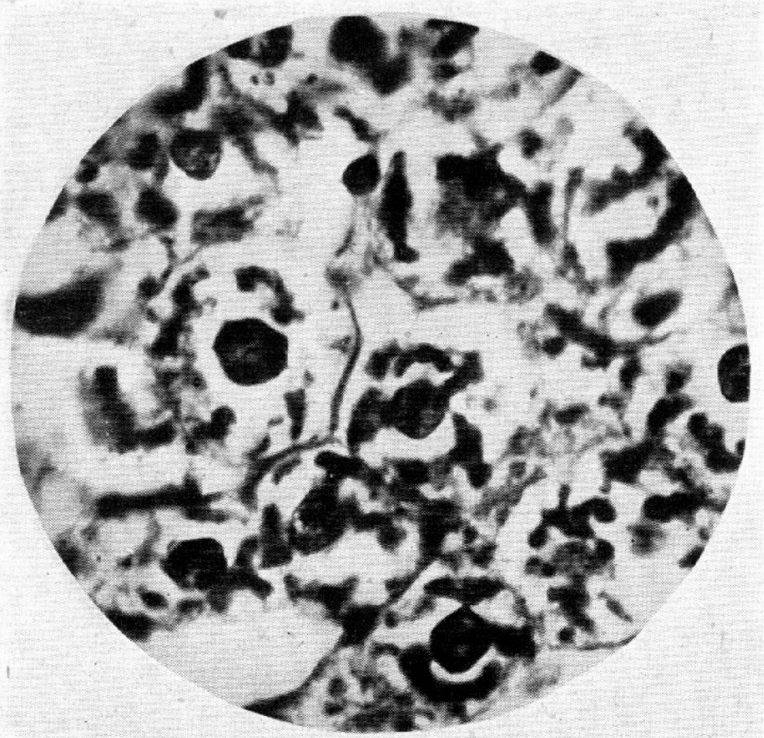

Fig. 1. - "Carbowax" section of rat liver stained with toluidine blue showing basophilic masses in the cytoplasm, $\times 630$.

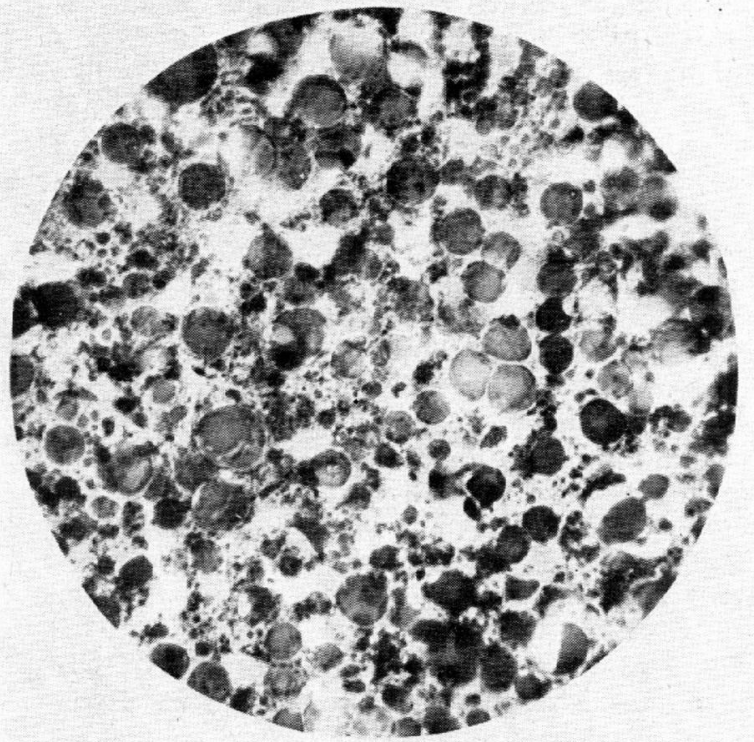

FIG. 3.-“" Carbowax" section of liver stained for fat with Sudan IV in propylene glycol from a case of nutritional oedema in an adult. The liver shows severe fatty infiltration and most of the fat droplets are stained, $\times 280$.

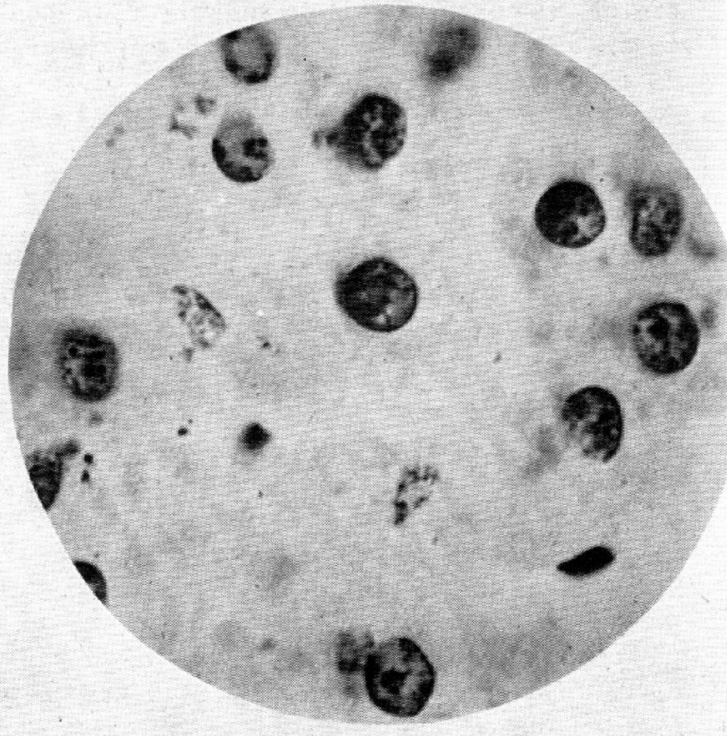

Fig, 2-" Carbowax" section of the same specimen as in Fig 1 stained with toluidine blue after treatment of the section with
ribonuclease at $37^{\circ}$ for one hour. No basophilic material is seen $\vec{\theta}$ in the cytoplasm, $\times 630$.
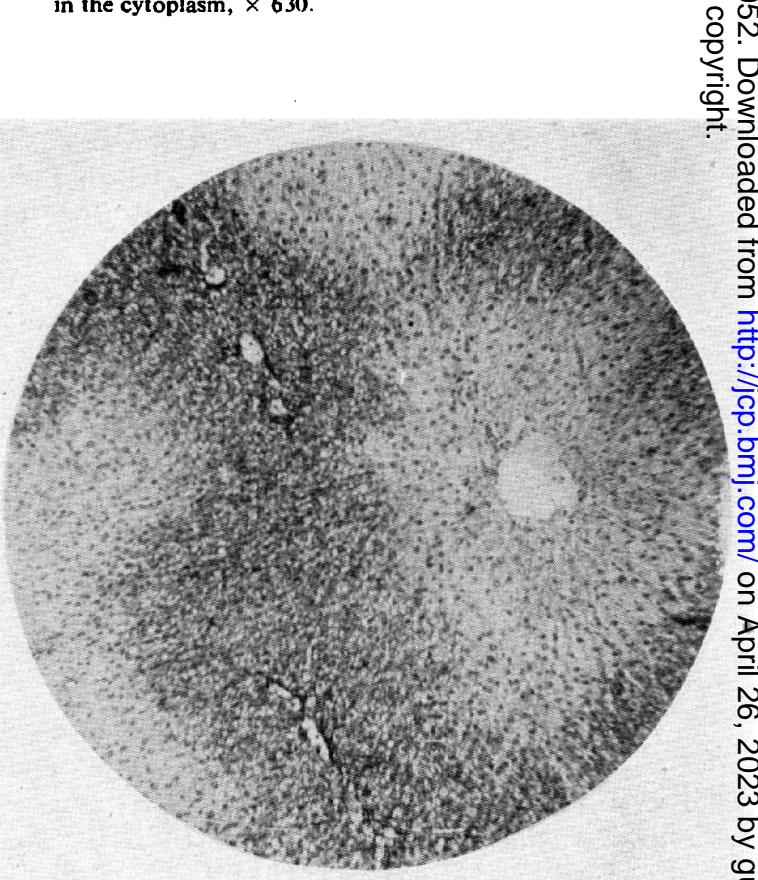
tetrachloride 72 hours before. The section has been stained for alkaline phosphatase by Gomori's method. Note the clear-cut 7 zonal distribution of the reaction, centrilobular zones showing no zonal distribution of the reaction, centrilobular zones showing no
reaction (except in nuclei) and periportal zones showing a marked one, $\times 70$.
FIG. 4.- "Carbowax" section of liver of a rat injected with carbon $\mathbb{E}$ 


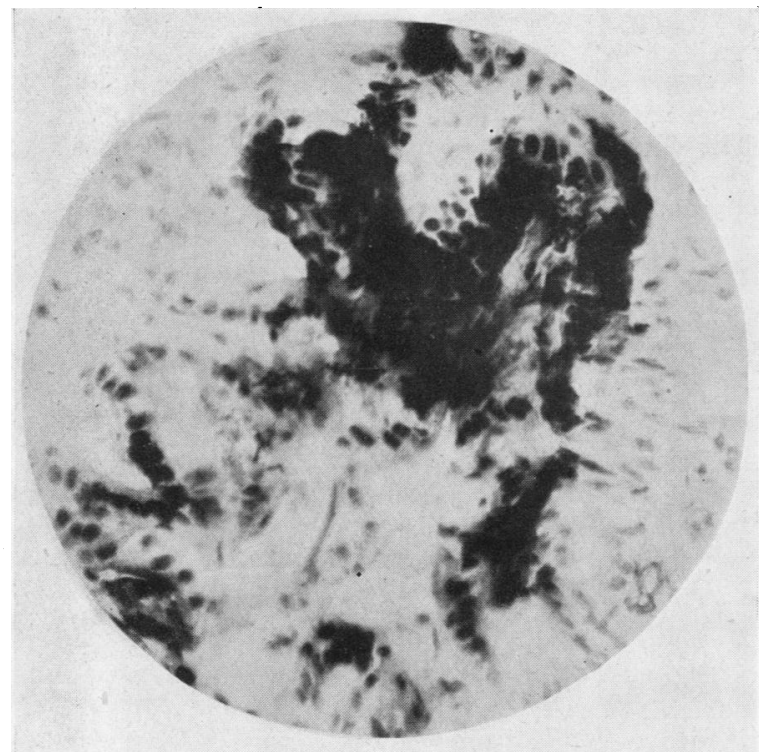

FIG. 5- "Carbowax" section of rat prostate stained for acid phosphatase according to Gomori. Sites of acid phosphatase activity are seen as dark deposits. The section has been counterstained with safranine, $\times 280$.

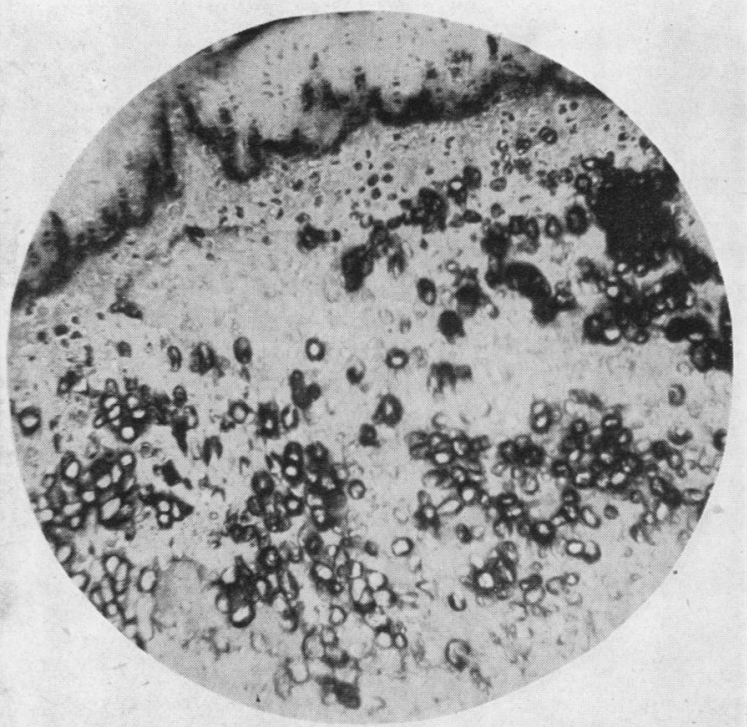

FIG. 7.- "Carbowax" section of tibial cartilage of a rachitic rat stained for alkaline phosphatase according to Gomori. The immature zone is relatively free from the enzyme but the mature zone shows large quantities of it, $\times 70$.

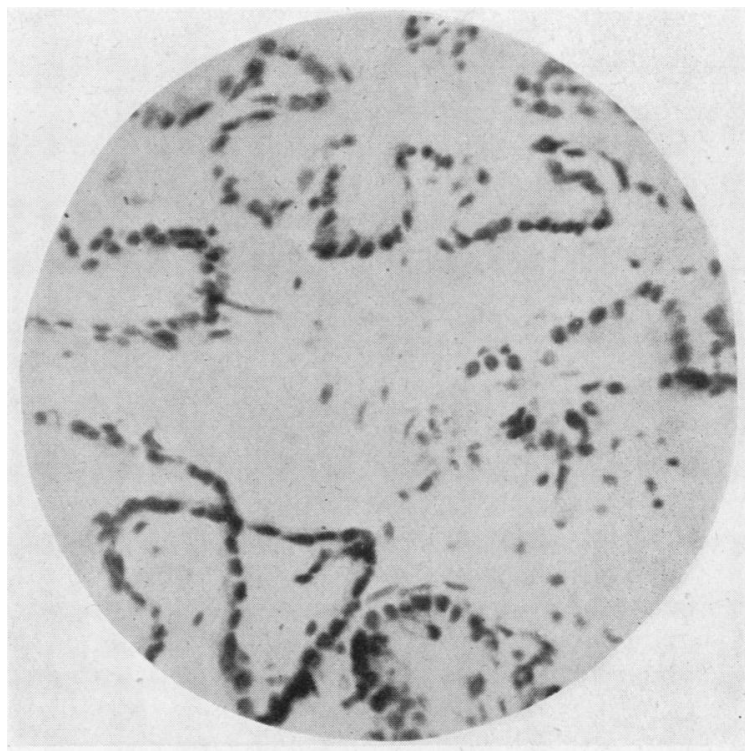

Fig. 6. - "Carbowax" section of same specimen as in Fig. 5, stained for acid phosphatase according to Gomori after inactivation of the phosphatase in $0.25 \%$ solution of nitric acid. There are no dark deposits. The section has been counterstained with safranine, $\times 280$.

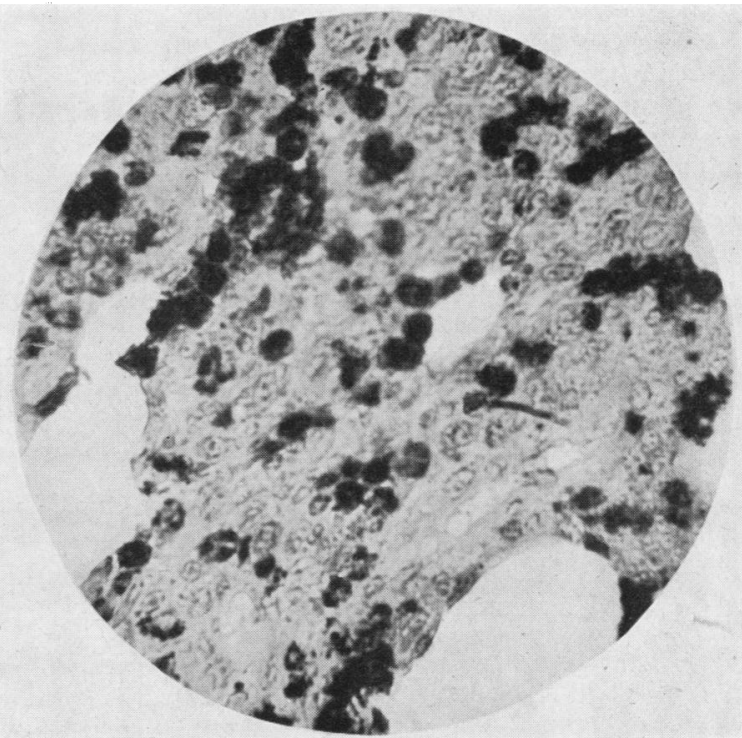

FIG. 8.- "Carbowax" section of guinea-pig lung stained for oxidase by the Winkler-Schultze method showing dark, oxidase-positive leucocytes, $\times 420$. 
enzymes do not seem to be extracted from the lyophilised tissue by this water-soluble embedding material."

The distribution of fat, glycogen, nucleoproteins, ribonucleic-acid protein (R.N.A.) and desoxyribonucleic-acid protein (D.N.A.), acid and alkaline phosphatase, oxidase and peroxidase in sections prepared by the more traditional methods have been the subject of study in this laboratory for some time. By employing the polyethylene glycol method we have been able to demonstrate these cell components in a more satisfactory manner.

\section{Material}

The material consisted of (a) samples of human liver obtained by needle biopsy from persons suffering from nutritional oedema; (b) livers of rats injected with carbon tetrachloride; $(c)$ cartilage and bones of rachitic rats, and $(d)$ lungs of guinea-pigs showing severe infiltration with eosinophilic leucocytes. Glycogen, fat, nucleoproteins (R.N.A. and D.N.A.), and alkaline phosphatase were studied in the livers and cartilages. Acid phosphatase was demonstrated in the prostate of normal rats. Oxidase and peroxidase reactions were demonstrated in granular leucocytes in guinea-pig lungs.

\section{Methods}

Fixation.-There is no single fixative suitable for the study of all cell components. In the absence of freezing dehydrating apparatus it was necessary to employ different fixatives for the satisfactory demonstration of particular cell components. Thin slices of tissue under $3 \mathrm{~mm}$. thickness were used in all cases. For the demonstration of fat, oxidase, and peroxidase, the tissues were fixed in $10 \%$ neutral formalin for 12 to 24 hours. For nucleoprotein (R.N.A. and D.N.A.) 24 hours' fixation in $95 \%$ alcohol was employed. For glycogen, fixation in alcoholic formalin (1 part of formalin in 9 parts of absolute alcohol) for 24 hours was employed (Bensley, 1939). For the demonstration of acid and alkaline phosphatases, the methods of fixation recommended by Gomori (1951) were followed. For alkaline phosphatase the tissues were placed in ice-cold $80 \%$ alcohol and fixed for 12 to 24 hours in an ice-box. The same procedure was followed for acid phosphatase except that acetone was used in the place of $80 \%$ alcohol. It has been shown that enzymatic activity was preserved to the greatest extent by employing these fixatives, although considerable loss of acid phosphatase was still unavoidable (Danielli, 1946; Stafford and Atkinson, 1948 ; Rabinovitch, Junqueira, and Fajer, 1949).

Embedding.-After appropriate fixation the tissue is blotted and transferred directly into a bath of "carbowax 1000 " which is kept in an incubator at $40^{\circ}$ C. "Carbowax $1000 "$ melts completely at this temperature. After one hour the tissue is transferred to another bath of fresh " carbowax 1000," and after another hour is removed from the incubator and embedded in freshly melted "carbowax 1000 " using L-shaped metal pieces or paper boxes. The mould is then cooled for about 15 minutes in an ice-box where contact with moisture is avoided by enclosing it in a petri dish. The block, which becomes solid and can be easily separated from the mould by this time, is then trimmed and mounted on a specimenholder, wooden or metal, in the usual way as with paraffin blocks and is ready for sectioning. The time schedule given above for dehydration, infiltration, and embedding applies to" tissues of 2-3 $\mathrm{mm}$. thickness. Thicker specimens need a longer time for infiltration. "Carbowax" blocks should be stored out of contact with atmospheric moisture. They should be wrapped in cellophane paper and preserved in air-tight glass jars, preferably in an ice-box.

The procedure described above is essentially similar to that of Blank (1949). We found that for our climatic conditions during winter $\left(13.7^{\circ} \mathrm{C}\right.$.) " carbowax 1000 was superior to a mixture of "carbowax 4000 " and "carbowax $1540 "$ as recommended by Blank (1949). A small amount of "carbowax 4000 " was added with advantage to "carbowax 1000 " to make the blocks harder during summer $\left(18.6^{\circ} \mathrm{C}\right.$.). It was also observed that there was no advantage in passing the tissues through increasing concentrations of the "carbowax" in water during the process of dehydration.

Sectioning.-Sections as thin as $1 \mu$ have been obtained on a rotary microtome and, as a rule, no difficulty has been experienced in obtaining satisfactory ribbons. The sections are then floated in a dish of water when the wax dissolves quickly leaving the sections floating. They are then mounted on slides coated with egg albumen. The strong surface currents. set up during the solution of the wax in water may sometimes tend to disrupt thin, fragile sections. To overcome this difficulty, Firminger (1950) has suggested the use of a $5 \%$ solution of "carbowax" in water for floating sections. In our experience with " carbowax 1000 " the disruption of sections on floating in water was infrequent. By placing the ribbons directly on wet slides and draining the excess water, disruption of sections could be prevented. All sections are dried thoroughly overnight in an incubator at $37^{\circ} \mathrm{C}$. in order to affix the sections firmly to the slides.

Staining Methods.-Glycogen was stained by the periodic-acid leucofuchsin method (Lillie, 1948) and also by Best's carmine method. 'The results of both the methods were checked by running control sections which were exposed to human saliva for one hour to digest away the glycogen selectively. Fat was stained with Sudan IV in Herxheimer's solution in the usual manner and also with a saturated solution of the dye in propylene glycol according to the method of Chiffelle and Putt (1951). Ribonucleoprotein was stained with toluidine blue and the results were confirmed by pre-treatment of some of the sections with a $0.02 \%$ solution of ribonuclease at $37^{\circ} \mathrm{C}$. for one 
hour followed by toluidine blue staining. Crystalline ribonuclease was prepared from beef pancreas according to the method of Kunitz (1940). Desoxyribonucleoprotein was stained by the Feulgen technique (Feulgen, 1926). Alkaline and acid phosphatase were stained by Gomori's method (1951). To check false positive reactions control slides were always used in which either some essential constituent of the substrate solution was omitted or the enzyme was inactivated. In the case of alkaline phosphatase, glycerophosphate was omitted from the substrate solution, and in the case of acid phosphatase, the enzyme was inactivated by pretreatment of sections with $0.25 \%$ nitric acid for five minutes. Sites of oxidase activity were detected by the Winkler-Schultze method and of peroxidase activity by the benzidine peroxidase method (Lillie, (1948).

\section{Results and Discussion}

Some of the results are illustrated in Figs. 1 to 8 . Glycogen and nucleoproteins stained equally well by this method as by the usual paraffin method. Staining of fat in "carbowax" sections was superior to that in frozen sections as the sections were very much thinner. This made the localization of sudanophilic material in relation to cell components more exact. The method of Chiffelle and Putt (1951), using propylene glycol as the vehicle for Sudan IV, gave better results than the older method which employs Herxheimer's solution. By this method more fat globules were stained and the intensity of staining was improved. Similarly, the staining for acid and alkaline phosphatase was more intense in the carbowax method than in the paraffin method, although the pattern of distribution of their activity was similar in sections obtained by the two methods. This is probably attributable to the shortened period of dehydration and infiltration of the tissues and their exposure to a much lower temperature $\left(40^{\circ} \mathrm{C}\right.$. $)$ than with the paraffin method $\left(56^{\circ} \mathrm{C}\right.$. $)$.

With the "carbowax" method dehydration, infiltration, and embedding are achieved with the same agent and the entire process is completed within a few hours. This advantage is common to all types of work, whether general or histochemical, but is particularly valuable for histochemical studies. As far as the demonstration of lipoids within cells is concerned, the carbowax technique seems to be already the method of choice (Firminger, 1950 ; Rinehart and Abul-Haj, 1951). In addition, it is technically useful when handling tiny biopsy specimens of liver for showing fatty infiltration and following its regression on treatment as it is extremely difficult to make frozen sections of these fragments.

For the histochemical demonstration of those enzymes which we have investigated, carbowax embedding is by far the best method. The advantages of this method over the paraffin embedding technique are: (1) The specimens need not be passed through alcohols and the usual clearing agents used for preparation of paraffin sections ; (2) the temperature of the infiltrating and embedding baths need not be higher than $40^{\circ} \mathrm{C}$; and (3) the time of incubation in the baths is relatively short. All these factors are important for the preservation of enzymes in the tissues. The loss of enzymatic activity which is known to occur during paraffin embedding of tissues is considerably reduced by this method. However, it must be pointed out that this method does not necessarily ensure accurate localization of enzymatic activity in cells, which continues to be a major drawback in all histochemical work dealing with enzymes.

The method is not free from disadvantages. Chief among them is that it is difficult to obtain ribbons consistent with every type of tissue and that serial sections cannot always be guaranteed.

\section{Summary and Conclusions}

A variety of animal and human tissues was dehydrated, infiltrated, and sectioned in solid, waxlike polyethylene glycol compounds.

Glycogen, fat, nucleoproteins, acid phosphatase, alkaline phosphatase, oxidase, and peroxidase were demonstrated.

For some histochemical purpose the polyethylene glycol technique possesses advantages over the earlier methods of preparing the sections.

We are indebted to the National Carbon Company (India) Ltd., representative of the Carbide and Carbon Chemicals Corporation, New York, for their generous gift of "carbowax." Our thanks are due to Dr. $H$. Lehmann, of St. Bartholomew's Hospital, London, for his interest and helpful criticism. The guinea-pig lungs were kindly supplied by Dr. I. G. K. Menon, Pasteur Institute, Coonoor.

\section{REFERENCES}

Bensley, C. M. (1939). Stain Technol., 14, 47.

Blank, H. (1949). J. invest. Derm., 12, 95.

Cand McCarthy, P. L. (1950). J. Lab. clin. Med., 36, 776.

Carsten. M. E. (1947). Arch. Path., 44, 96.

Chiffelle, T. L., and Putt, F. A. (1951). Stain Technol., 26, 51.

Danielli, J. F. (1946). J. exp. Biol., 22, 110

Feu'gen, R. (1926). Quoted by Gomori, G. (1951).

Firminger, H. I. (1950). St.rin Technol., 25, 121.

Gomori, G. (1946). Amer. J. clin. Path., 16, 347.

(1951). Meth. med. Res., 4, p. 1.

Holter, H., and Linderström-Lang, K. (1951). Physiol. Rev., 31, 432 Kunitz, M. (1940). J. gen. Physiol., 24, 15.

Lillie. R. D. (1948). Histopathologic Technic. Philadelphia and Toronto

Montagna, W., and Noback, C. R. (1947). Science, 106, 19. Rabinovitch, M., Junqueira, L. C., and Fajer, A. (1949). Stain

Rheingo'd, J. J., and Wis'ocki, G. B. (1948). Blood, 3, 641.

Richards, A. G., Anderson, T. F., and Hance, R. T. (1942). Proc. Soc. exp. Biol... 51, 148 .

Stafford, J. F., and Abul-Haj, S. (1951). Arch. Path., 51, 666.

Stafford, R. O., and Atkinson, W. B. (1948). Science, 107, 279. 